with Ecological Momentary Assessment

\author{
Reuma Gadassi Polack ${ }^{1}$, Gabriela Paganini ${ }^{1}$, Julia Winschel ${ }^{1}$, Hadas Benisty ${ }^{1}$, Jutta \\ Joormann ${ }^{1}$, Hedy Kober ${ }^{1}$, \& Gal Mishne ${ }^{2}$ \\ ${ }^{1}$ Yale University \\ ${ }^{2}$ University of California, San Diego
}

(

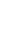

\title{
Abstract
}

Magnetic resonance imaging (MRI) and Ecological Momentary Assessment (EMA) are two powerful methods to study psychological processes that have become increasingly popular in the last two decades. Though each method is valuable in its own right, their complementary strengths have the potential to further advance our understanding of typical and atypical human behavior. Despite the increase in the number of studies that combine these methods over the last decade, there are no existing recommendations for best practices or norms for conducting and reporting the findings from these types of studies. To address the absence of such standards in the field, we conducted a systematic review of papers that combine these methods. A systematic search of peer-reviewed papers using Google Scholar resulted in a pool of 11,558 articles. Inclusion criteria were 1) data-based study in which 2) participants completed (a) Structural or functional MRI and (b) an EMA protocol that included self-report. Seventy-one papers met inclusion criteria. The following review compares these studies based on several key parameters (e.g., population age and type, type of MRI scans and EMA assessments, sample size) with the aim of determining feasibility and current standards for design and reporting in the field. The 
23 review concludes with recommendations for future research guidelines. A special focus is given

24 to the ways in which the two methods are combined on an analytical level and suggestions for

25 novel computational methods that could further advance the field.

26 Keywords: Magnetic Resonance Imaging, Experience Sampling Methods, Ecological

27 Momentary Assessment, Daily-Diaries, Ambulatory Assessment

30 Author's Note

31 The present study National Institute of Mental Health Translational Developmental Neuroscience

32 Training Grant (T32 \#MH18268), The Israeli Council for Higher Education Postdoctoral

33 Research Fellowship for Women, and the Marie Sklodowska-Curie Individual Fellowship

34 (786460) under the European Union's Horizon 2020 research and innovation program awarded

35 to Dr. Gadassi Polack, the National Institute of Mental Health R21 MH119552 awarded to Dr.

36 Joormann and Dr. Kober. The authors thank Jessica Molick, Uri Berger, and Itay Polack Gadassi

37 for their help with data collection.

38 


\section{Better together: A systematic review of studies combining Magnetic Resonance Imaging} with Ecological Momentary Assessment questionnaires can be used to probe subjective experience or behavioral intentions. However, such data may be incomplete, as mental processes may be inaccessible to conscious awareness or biased. Even when information is accessible, it is not always shared accurately (e.g., due to social desirability). To circumvent these challenges, researchers have often turned to otherobjective - measures, such as physiological assessments (e.g., heart-rate variability), hormonal assessments (e.g., cortisol), and neuroimaging (e.g., functional magnetic resonance imaging [fMRI]). However, translating the results from such objective into meaningful conclusions about subjective experience is not straightforward. Conducting a multimethod (or multimodal) study is one obvious solution for addressing this translational challenge. The current review focuses on studies that combine two powerful methods for measurement of subjective behavior and objective assessment of mental processes: Ecological Momentary Assessment (EMA) and structural and functional Magnetic Resonance Imaging (for brevity sake, we use MRI for both).

MRI: Tapping into mental processes at the source. Using MRI, we can learn whether different tasks engage common or distinct mental processes, we can pinpoint specialized mechanisms that underlie particular mental processes, and we can learn how different stimuli are represented in the mind (e.g., Bassett et al., 2020; Brooks et al., 2017; Matejko \& Ansari, 2018; Mather et al., 2013; Schurz et al., 2021; Zilverstand et al., 2017). Of course, MRI has several limitations (e.g., Elliott et al., 2020; Hall et al., 2016; Logothetis, 2008; Mather et al., 2013; Poldrack, 2011; Shamay-Tsoory \& Mendehlson, 2019). Of relevance to the current review, a major limitation of MRI is ecological validity. The measurement of neural activation when 
63 individuals are mostly passive, practically immobile, and socially deprived is highly problematic

64 (Shamay-Tsoory \& Mendehlson, 2019). A related limitation is the fact that MRI scans are

65 conducted typically once in a highly-controlled environments, which is at odds with our

66 knowledge that human behavior is highly situation-dependent (Mischel \& Shoda, 1995). These

67 challenges limit the external validity and clinical utility of data collected with MRI.

EMA: Capturing dynamic processes in everyday life. EMA involves repeated

69

70

71

72

73

74

75

76

77 assessments of what naturally occurs in participants' everyday lives, typically by having them complete brief self-report assessments between one to several times a day over several days or weeks. As such, EMA is highly ecologically valid (Bolger \& Laurenceau, 2013). EMA is highly feasible in diverse populations and has unique scientific contribution (e.g., Russell \& Gajos, 2020; Strange et al., 2019). While discussing every advantage and disadvantage of EMA is beyond the scope of this review, we will note a few strengths that make it such a good counterpart to MRI. First, EMA allows us to study state and trait characteristics- i.e. we can simultaneously examine between-individual and within-individual processes, thus learning not only who experiences certain behaviors, but also when behaviors are experienced. Teasing apart state and trait and examining their interactions is crucial to psychological research in general (Mischel \& Shoda, 1995), and of particular importance in the context of clinical populations as this method can help us understand not only who is at risk but also when risk is more acute (Strange et al., 2019).

Second, although based on self-report, EMA can be utilized to assess psychological processes in an indirect way. For example, instead of asking individuals under which circumstances they do or feel certain things (e.g., harm themselves), EMA can infer the antecedence and consequence of behaviors by assessing what happened before and after the 
target behavior (e.g., Snir et al., 2015). Third, EMA can capture the dynamic aspects of variables - the pattern of change over time (e.g., emotional instability; Strange et al., 2019).

Along with its advantages, EMA has some limitations. First, it is essentially

observational; therefore, the results from EMA cannot be used to infer causality. However, statistical methods can help to determine directionality and reduce third-variable explanations (Bolger \& Laurenceau, 2013). Second, EMA is based on self-report, though the frequent assessments reduce memory biases, and repeated measurements reduce noise (Russ \& Gajos, 2020). Finally, its high ecological validity comes hand-in-hand with noise. Individuals are not exposed to the same events, thus many alternative explanations are possible. Statistical methods such as mean-centering help to alleviate some of these noise issues, but they do not correct them completely (Strange et al., 2019).

Better together: How MRI and EMA complement one another. MRI and EMA are a good combination as they address each other's limitations (Berkman et al., 2013; Wilson et al., 2014). MRI (brain structure or the BOLD signal) are objective measures, thus balancing the fact that EMA is reliant on subjective self-report. FMRI (similar to any task-based method) typically relies on standardized stimuli which increases internal reliability - thus complementing the unstandardized, idiosyncratic occurrences captured by EMA. Supplementing EMA to MRI can help examine brain-behavior links and translate MRI findings to everyday life. The two methods also complement each-other's time scale: fMRI captures online-real time processes that occur over seconds or minutes - EMA captures processes that occur over hours and days.

\section{The present study}

The goal of the current systematic review is twofold. First, we aim to describe the current state of research combining MRI and EMA. We do so by examining the logistics of the studies 
109 (e.g., design, number of measurements etc.), as well as a description of more essential topics

110 (e.g., which constructs are assessed via each method). Second, we make several

111 recommendations in an attempt to provide future research teams with explicit guidelines and

112 questions to consider when planning this type of study.

Method

We carried out a systematic review following the recommendations of the Preferred

115

116

117

118

119

120

121

122

123

124

125

126

127

128

129

130

131

Reporting Items for Systematic Reviews and Meta-Analyses (PRISMA) statement (Liberatti et al., 2009).

Study selection criteria. Studies were eligible for inclusion if they met the following criteria: Participants' data included (1) structural or functional MRI scan and (2) EMA. Our definition of EMA included repeated assessments at least once a day for at least three consecutive days. Studies in which EMA and MRI were completed by different sets of participants were excluded; (3) EMA protocol had to include a self-report component. Studies including only passive sensing (e.g., GPS) were excluded, as we were interested in the measurement of subjective experience (see Camacho et al., [2021] for a review of studies combining MRI with passive sensing); (4) Participants were neurologically intact; studies on populations with neurological conditions (e.g., stroke) were excluded; (5) papers were written in English; and were (6) published in peer-reviewed journals.

Search strategy, study selection and data extraction. We searched scholar.google.com using the following search string: (EMA OR ESM OR "ecological momentary assessment" OR "experience sampling method") AND (fMRI OR neuroimag* OR “functional MRI” OR “functional magnetic resonance imaging”). Since Google Scholar presents a maximum of 1,000 results per search, we searched by year for the years 1996-2020 (including). Search results from 
132 each year were downloaded into CSV files and inspected manually. The search was completed

133 by May 2019 and updated (including forward and backward searches) in June 2021. Figure 1

134 presents the PRISMA flow diagram for study selection and exclusion process. Table S1 includes

135 full-text articles excluded with reasons. Articles were coded according to joint characteristics

136 (e.g., sample size, number of MRI scans) by two coders (one of them was the first author), and

137 discrepancies were resolved by discussion. Table S2 in supplementary materials includes the full 138 list of papers and characteristics that were coded.

Seventy-one published papers were included in this systematic review, summarized in

141 Table 1. As can be seen in Figure 2, the majority of papers (40 papers; $56 \%$ ) were published in

142 the last four years, indicating a trend of increased use of this specific multimethod design.

143 1. Practical issues

144 1.1. Participants

Sample size varied between studies, with an average number of 50.94 participants

$146(S D=37.02$, Median=45, range $=16-294)$. Retention rate could be computed for studies that

147 provided the initial number of participants (47 studies, 66.20\%). Retention rates were high

$148(M=0.75, S D=0.17$, Median $=0.83$, range $=0.33-0.94)$. Sample size justification was not provided

149 for most of the studies $(\mathrm{N}=60 ; 84.5 \%)$. Of those that justified sample size, six papers justified

150 sample size by what is within standards from previous literature. Five studies $(7 \%)$ conducted a

151 power analysis. None of the papers reported the amount of time it took to recruit the samples.

152 One thing that may influence retention is participant compensation. Of the 71 papers

153 included in this review, half $(\mathrm{N}=36,51.70 \%)$ provided information regarding participant

154 compensation. Of those, $25(35.21 \%)$ only stated that participants were compensated without 
155 reporting the amount. Eleven papers (15.49\%) reported the maximum total payment that

156 participants could receive for their participation. For these papers, the average maximum amount

157 of payment was $\$ 140.69$ (range $=\$ 46-\$ 400)$. In seven papers the maximum payment available

158 was contingent upon compliance to the EMA protocol. Finally, three papers offered participants

159 alternative means of compensation in addition to monetary reward: experimental hours for study

160 plans (Martin-Soelch et al. 2020), referral information for local psychological services (Kaiser et

161 al. 2019), or course credit (Chester \& DeWall 2014).

162

163

164

165

166

167

168

169

170

171

172

173

174

175

\subsection{Measurement}

1.2.1. MRI. Participants typically completed one MRI scanning session ( $\mathrm{N}=66$ papers; 93\%). Five papers (7\%) asked participants to be scanned twice. Most of the papers included a task-based fMRI $(\mathrm{N}=60 ; 85 \%)$, seven papers $(10 \%)$ had participants complete resting-state fMRI, three papers (4\%) used structural MRI or diffusion tensor imaging, and one paper (1\%) used structural, resting state, and task-based fMRI scans.

1.2.2. EMA. On average, participants completed a 13.24 days-long EMA protocol $(S D=12.78$, Median=14, range $4-105)$ with a mean of 4.62 daily assessments $(S D=4.18$, Median=3, range 1-25), generating an average total of 46.82 separate assessments per paper $(S D=42.95, \text { Median=28, range 5-250 })^{1}$.

\subsection{Publication Impact}

To assess the quality of publications based on MRI-EMA we retrieved journal impact factors for the year 2020 from Journal Citation Reports for each publication outlet. The average impact factor of the journals was high $($ Mean=6.09, $S D=4.46$, Median=4.88, range: $2.08-24.88)$.

\footnotetext{
${ }^{1}$ Numbers reported here are the maximum number of assessments required from the participants, unless that was not provided (e.g., in event-contingent design), and the average number of assessments completed by participants was reported.
} 
176 Another metric when considering the impact of a publication is examining how well-cited it is.

177 To assess that, we extracted from scholar.google.com the number of times each paper was cited.

178 Since the number of years that have passed since publication greatly influences number of

179 citations $(r[71]=.748, p<.0001)$, we computed the number of citations per year. Across the 71

180 papers included in the review, the average number of citations per year was $9.40(S D=9.46$,

181 Median=6.25, range 0-45.4).

\section{1.4. Number of authors \& research groups}

183

184 185

\section{Combining methods requires a research team with expertise in both methods. The} average number of authors of the papers in this review was $6.23(S D=2.94$, Median=6, range 214). Not all studies reported if they originated from the same datasets; however, by extracting the location of the study from the university who gave the IRB approval, we were able to assess, as can be seen in Figure 3, that the 71 papers included in the review originated from 30 universities and medical centers. Many studies originated at the University of Pittsburgh $(\mathrm{N}=12,16.90 \%)$ and UCLA $(\mathrm{N}=11,15.49 \%)$. Based on this information, we can say with some certainty that 21 papers $(30 \%)$ were the single publication from their datasets.

\section{Thematic issues}

\subsection{Population}

As can be seen in Table 1, the populations studied using the MRI-EMA combination are diverse: the age range of participants spanned from 8 years to 69 years, with 27 papers (38.0\%) including participants younger than 18 years. Thirty-three papers $(46.48 \%)$ focused on populations that was either diagnosed with current or at risk for a psychiatric disorder, or with a psychopathology-related traits (e.g., chronic dieters). In other words, most of the studies included 
198 in the review $(\mathrm{N}=51,72 \%)$ focused on clinical and/or developmental populations or romantic 199 couples, and only $28 \%$ of papers focused on populations considered as easily recruited.

200

201

202

203

204

205

206

207

208

209

210

211

212

213

214

215

\subsection{Psychological constructs}

EMA constructs. Using EMA, the most frequently assessed construct was daily affect/stress $(\mathrm{N}=51,71.8 \%)$, followed by social interactions $(\mathrm{N}=26 ; 36.6 \%)$. Two additional frequent themes were self-regulation/craving/consumption of substances (including alcohol, cigarettes, and food; $\mathrm{N}=14 ; 19.7 \%)$, and psychopathology symptoms $(\mathrm{N}=11 ; 16 \%)$. Additional constructs were sleep quality $(\mathrm{N}=5 ; 7 \%)$, reward processing $(\mathrm{N}=4 ; 6 \%)$, and self-esteem $(\mathrm{N}=3$; 4\%). Most EMA protocols assessed more than one construct.

MRI constructs. Using task-based fMRI, the constructs most commonly assessed were social $(\mathrm{N}=21,30 \%)$ and emotional $(\mathrm{N}=16,22 \%)$, followed by inhibition/self-regulation in response to stimuli (either non-emotional or of appetizing stimuli such as alcohol; $N=14,20 \%$ ), reward processing ${ }^{2}(\mathrm{~N}=13,18 \%)$, and risk taking $(\mathrm{N}=3,4 \%)$.

\section{Combining MRI and EMA}

When conducting a multimethod study, the research team must make decisions regarding three topics: (1) the order that participants will complete measurements, (2) will the different methods assess the same constructs, and (3) analytical techniques used to analyze the data from two different sources.

\subsection{Design considerations: Order of measurement}

We identified four research designs: (a) MRI first, followed by EMA. This order was used by 33 of the papers $(46 \%)$, with one of the papers reporting a subtype in which this order was repeated twice - once prior to and once following an intervention (Chen et al., 2018). (b) EMA

\footnotetext{
${ }^{2}$ Social reward task counted under social as well as under reward processing
} 
220 first, followed by MRI. This sequence was used by 24 of the papers (34\%). (c) MRI scans during

221 EMA period. In four studies (6\%) participants completed a baseline period of EMA to assess

222 mean stress levels and were invited for two MRI scans within the EMA period - one scan on a

223 day when they experienced lower than their baseline level of stress, and a second scan on a day

224 when they experienced higher than their typical level of stress (e.g., Uy \& Galván, 2017a). The

225 four papers originated from the same research group and may have resulted from the same

226 dataset. (d) In five papers (7\%) participants completed the two methods in varying orders. One of

227 them (Grosse Rueschkamp et al., 2019) counterbalanced the order of the MRI and EMA so that

228 about half of the participants completed the EMA first, and the other half completed the MRI

229 first. Finally, five papers (7\%) did not report any information regarding the order in which

230 participants completed the methods.

In addition to deciding the order that participants will complete EMA and MRI, research teams must also establish the time gap between the two methods. Most studies reported no time gap i.e., (EMA was started the day of the scan) or minimal times lag (e.g., EMA was completed

234 within days or weeks of the scan). A large minority of the papers $(\mathrm{N}=24 ; 34 \%)$ did not provide any information on the time gap between methods.

\subsection{Similarities in measured constructs}

Another issue that when planning a multimethod study is whether the same construct was

238 measured using the two methods. Constructs were similar in both methods in $86 \%$ of the papers

239 that used fMRI to assess inhibition/craving, $87.5 \%$ of the papers that used fMRI to assess

240 emotion processing/regulation, $71.4 \%$ of the studies that used fMRI to assess social constructs,

$24131 \%$ of the studies that used fMRI to assess reward processing, and none of the studies that used

242 fMRI to assess risk-taking. 


\subsection{Increasing the ecological validity of fMRI tasks}

Several research teams made explicit efforts to bring "real life" into the scanner. This trend of increasing the ecological validity of the fMRI has become increasingly popular in recent years (e.g., in our review, since 2018).

3.3.1. Using individualized stimuli. One option for bringing "real life" into the scanner is using familiar people as stimuli, thus allowing researchers to assess participants' neural responses to meaningful, personalized stimuli in addition to the EMA. Five papers adopted this strategy (Alcaron et al., 2020; Dodell-Feder et al., 2016; Hooker et al., 2010; Vekaria et al., 2020; Woods et al., 2020). For example, Hooker et al., (2010) focused on committed couples and examined how each partner reacted to the other's emotional facial expressions.

3.3.2. Bringing the social context into the lab. Another option for bringing "real life" into the scanner is scanning participants' close others. Four papers included in the current review (6\%) adopted this strategy. Two of these papers focused on committed couples (Dodell-Feder et al., 2016; Hooker et al., 2010), and two (Lee et al., 2017a, 2017b) focused on parent-child dyads. All four studies had dyad members complete the EMA simultaneously, allowing the researchers to track interpersonal effects of neural responses.

\subsection{Analytic methods}

In this section we characterize how papers combined the two methods analytically. It should be noted that the vast majority ( $\mathrm{N}=68,95.77 \%)$ of the papers included in the review reported statistically significant associations between the two methods, suggesting the value of combining the methods for gaining understanding of certain behavioral processes.

3.4.1. Brain-EMA correlations: Averaging over time. The simplest way of combining EMA data with MRI data was averaging across the EMA period and computing a correlation 
266 between the EMA variable and activation in a Region of Interest (ROI). For example, Forbes et

267 al. (2009) examined the associations between mean positive affect across the EMA period and

268 activation in striatal clusters in response to reward. For 16 of the papers in this review (22\%),

269 this was the only strategy used to analytically combine methods. Eight papers used it as a

270 secondary strategy.

271

3.4.1.1. Brain activity as a mediator. A subtype of the studies that

272 compute averages from across the diary period used brain activation as a mediator (i.e., a

273 variable that accounts for the association between two other variables; Hayes, 2017).

274 Specifically, these papers examined neural activation as a mediator between the averaged EMA

275 variable and an additional variable. For example, Price et al. (2016) examined if amygdala-

276 dlPFC connectivity mediated the relationship between attentional vigilance during a task and

277 distraction during the EMA. Four papers in the review (6\%) used this analytic strategy.

3.4.2. Dynamic average. Whereas a simple average is an aggregate of mean levels,

279 EMA can be used to capture changes over time, or the dynamic aspects of processes which are

280 difficult to capture otherwise (Strange et al., 2019). Twenty-one papers (30\%) combined MRI

281 and EMA by extracting these types of variables from the EMA. The largest fraction of these

282 papers used EMA to assess constructs related to emotional dynamics (e.g., affective instability;

283 Servaas et al 2017 \& Provenzano et al 2018). Other variables computed using this strategy were

284 changes in sleep quality from weekdays to weekend (Hasler et al., 2012), the chronicity of peer

285 conflict (Telzer et al., 2015), the proportion of food desire enactment (Lopez et al., 2017), and

286 the proportion of helping familiar vs. unfamiliar people (Vekaria et al., 2020). Another analytic

287 options we include in this category is instances in which researchers extracted the correlations 
288 between two variables, such as social distress and social disconnection (Eisenberger, Gable et al., 2007), and then examined if these associations were related to averaged neural activation.

3.4.3. Brain as a moderator of momentary processes. The most common method for analytically combining the methods was examining if neural activation moderates the associations between momentary variables, thus examining Person (or brain region) by Situation interaction. A moderating variable is a variable that influences the strength of the association between two other variables (Hayes, 2017). For example, Hooker et al. (2010) examined if neural activation while watching a romantic partner's negative (vs. positive) emotional expressions moderated the associations between daily interpersonal conflict and mood. Of the papers included in this review, $22(31 \%)$ used this analytic strategy.

3.4.4. EMA moderates neural processes. Five papers (7\%) analyzed EMA as a moderator of neural responses. One study (Bourne et al., 2013) had participants watch clips of potentially traumatic videos during fMRI, and then complete an EMA entry every time they experienced a flashback from a video they watched during the fMRI. The fMRI contrast compared videos that were classified as flashback-provoking were contrasted with videos that were not. The other four papers in this category had participants complete MRI scans on days when participants experienced stress levels that were higher or lower than their individually calculated averages as determined by the EMA (Rahdar \& \& Galván, 2014; Uy \& Galván, 2017a,b, 2020).

3.4.5. Dimension reduction across methods. One study (Giuliani et al., 2015) combined assessments from both methodologies using a factor analysis, thus proposing a type of multi-modal "dimension reduction". This study examined reactivity and regulation of food craving, and measured these constructs using self-report, EMA, and fMRI. Assessments from 
311 each method were extracted and entered into a principal component analysis. Then, results from

312 the factor analysis were entered into a regression analysis to predict food consumption.

\section{Discussion}

The current systematic review provides an organized account of common research

315

\section{Current practices: What do MRI-EMA studies typically look like?}

1.1. Who are the participants? The current review demonstrates that the combination of MRI and EMA is feasible and worthwhile even for populations that are difficult to recruit (developmental and psychiatric populations).

1.2. What are the main constructs? The constructs assessed most frequently were emotions and social interactions. Surprisingly, there was not always an overlap in constructs assessed using the two methods. Assesing the same construct in both methods allows for replication and can contribute to construct and convergent validity. Moreover, from a multimodal perspective, using different methods to capture similar processes allows us, assuming that the process is shared, to find meaningful shared variance across modalities. A related point is that while MRI typically assessed a single psychological construct, the EMA typically examined multiple constructs. The relative ease of assessing additional constructs via EMA can be leveraged in future studies to determine the convergent and divergent validity of MRI by examining which constructs can be predicted by neural activation and which ones cannot.

1.3. Methodological choices. Across studies, there was variation in the order in which the methods were used, with a slight preference to conducting the MRI first. Although temporal 
334 precedence is not sufficient to deduce causality, it provides evidence of directionality from brain 335 activation to behavior and predictive validity for neural structure or activation. Only one study

336 counter-balanced the order of method - this variation is important as it helps rule out (or 337 mitigate) order effects of the methods.

1.4. Analytical choices. Many of the studies used neural activation as a moderator of 339 daily processes, thus adopting a Person by Situation examination of processes. In contrast, several studies extracted variables from the EMA that capture the dynamic nature of psychological processes (e.g., emotion instability). Still, many other studies extracted an average

342 across the EMA period and correlated it with averaged neural activation. Interestingly, two 343 studies used processes assessed by EMA to determine the timing of MRI scans (Rahdar \& 344 Galván, 2014; Uy \& Galván, 2017a) or to determine how MRI contrasts were computed (Bourne 345 et al.,; 2013). Only one paper attempted to converge data across methods (Giuliani et al., 2015) using a multivariate approach. Almost all of the papers reported at least one significant finding.

347 Significant associations between levels of analysis are not trivial, considering that the method of 348 assessment often impacts results (e.g., Avinun \& Knafo, 2014) and that coherence across levels 349 can be weak (e.g., Mauss \& Robinson, 2009).

2. Reporting limitations \& recommendations. Multimethod studies are incredibly 351 complex; understandably, not all the details are always reported. However, in many of the 352 papers, specific information regarding study design was missing (e.g., time required to recruit 353 sample, number of publications from the same dataset). This information could be helpful for 354 researchers planning to conduct similar studies. Additionally, some of the details that are 355 commonly unreported may impact interpretation of the results; for example, not all studies report 
356 the time gap between the methods. A possible solution for this issue could be inclusion of a

357 detailed study protocol in an online platform (e.g., OSF).

A second common limitation across the papers we reviewed is that sample sizes were

359 rarely justified, and the use of a-priori power analyses was even rarer. The inclusion of power analyses is necessary for the field to advance. Relatedly, pre-registration of research hypotheses

361 was not reported in any of the included studies. This is a notable issue because both MRI and 362 EMA produce rich datasets, especially when combined. This issue, together with the typically-

363 limited sample sizes in studies of this kind, raises questions regarding the robustness and 364 reproducibility of the effects found in these studies.

366 consist of hundreds of features, i.e., they are high-dimensional data sets. The richness of the

367 dataset may also raise concerns about the robustness of the findings. Therefore, we believe that

368 in addition to pre-registered, hypotheses-driven analysis, researchers should consider

369 multimodal, data-driven methods. Data driven approaches include (but are not limited to)

370 multimodal modeling and analyses, pattern recognition and machine learning. We present here

371 several recommendations for analysis approaches that can combine EMA and MRI and help

372 uncover patterns that emerge from the integration of these two modalities. Computational data-

373 driven methods can be divided into two categories: a) Supervised methods aiming to train

374 parametric models based on a-priori knowledge and/or external labels values. b) Unsupervised

375 methods which are data-driven approaches for extracting alternative parsimonious

376 representations for the data, thus simplifying further analysis and enabling meaningful

377 visualization. 
Supervised methods can be extremely efficient and easy to implement for establishing a

379

380

381

382

383

384

385

386

387

388

389

390

391

392

393

394

395

396

397

398

399

400 statistical relation between EMA and MRI data and other external features such as clinical

diagnosis, age, gender, etc. When training a supervised model (for example prediction, classification or regression; James et al., 2013) one modality can take the part of the input variable (i.e., independent variable) used to predict a feature taken from the other modality taking the part of the outcome variable. For example, EMA features can be used to predict whether a specific brain region is activated or not, or if two brain regions are highly connected or not. This can be done, for example, in a diagnosed group vs. a healthy control group to demonstrate statistical relations between EMA and brain activity in different populations. The large number of features in EMA and MRI studies presents a great challenge deciding which features are important. Feature selection, which is part of the supervised methods, provides a way of making that decision (Park \& Casella, 2008; Kohavi \& John, 1997; Zou \& Hastie, 2005; Yamada et al, 2020). These methods are based on training an optimization model (for example classification or regression) while restricting the number of features used. Feature selection methods provide two major advantages: i) Model interpretability: a consistent quantification of the importance of each input feature with respect to the trained task. ii) Regularization: in many cases the number of features is large relatively to the sample size, which may cause overfitting (i.e., the trained model is unable to generalize and describe unseen data). Feature selection would help reduce overfitting.

Unsupervised methods are also used to extract a low dimensional representation capturing the major trends and patterns of each modality can be useful as a pre-processing stage, but without an external variable guiding the dimension-reduction. The most straightforward approach is to use dimensionality reduction methods such as Principal Component Analysis 
401 (PCA) or kernel-based methods (Belkin \& Niyogi, 2003, Coifman \& Lafon, 2006). The extracted 402 representations can facilitate easier visualization of the data sets, as well as training and 403 implementation of pattern recognition and clustering algorithms such as k-means or Gaussian

404 Mixture Models (GMM) used for establishing a statistical relation between the detected patterns 405 across participants between the two modalities.

406 A more advanced approach is to use multiview (also called multimodal) analysis such as 407 Canonical Component Analysis (CCA) (Hardoon et al., 2004). The multiview paradigm requires 408 a joint dimension, such as participants, that are "observed" through different "views" (or 409 modalities), e.g., EMA and MRI. Each view yields different features and multiview analysis 410 reveals information that is shared by the two views. As a specific example, the aim of CCA is to 411 calculate a linear transformation of the features from each modality to a low-dimensional joint 412 space such that the correlation, across participants, between the new (low dimensional)

413 representations is maximized. CCA also provides an interpretable transformation indicating 414 which features of each modality are most correlated with the joint space (i.e. with the global 415 pattern detected by the CCA). Non-linear variates of CCA such as kernel CCA (Schölkopf et al., 416 1998; Michaeli et al., 2016; Lindenbaum et al., 2020), may provide better modeling when linear 417 approaches fail to capture the intrinsic relations between the two modalities; however, they are 418 not able to provide the same interpretability capabilities provided by linear approaches. Both 419 linear and non-linear unsupervised methods for dimensionality reduction allow us to visualize 420 the data and measure statistics such as clustering or prediction or regression of an external 421 variable, such as age or clinical group membership.

422

Summary. The current review describes common research practices, advantages, and 424 limitations of studies that combine MRI and EMA. We demonstrate how the distinct strengths 
425 and weaknesses of each method uniquely complement one another and help to generate

426 particularly impactful, clinically relevant research. Specifically, this combination increases the

427 clinical utility and ecological and predictive validities (and potentially the convergent and

428 divergent validities) of MRI studies. Though the combination of these methods is demanding,

429 both for research teams and study participants, this review demonstrates the practicality of

430 conducting such studies on diverse developmental and clinical populations. 
433

434

435

436

437

438

439

440

441

442

443

444

445

446

447

448

449

450

451

452

453

454

*References included in the systematic review

*Alarcón, G., Morgan, J. K., Allen, N. B., Sheeber, L., Silk, J. S., \& Forbes, E. E. (2020). Adolescent gender differences in neural reactivity to a friend's positive affect and real-world positive experiences in social contexts. Developmental Cognitive Neuroscience, 43, 100779.

Avinun, R., \& Knafo, A. (2014). Parenting as a reaction evoked by children's genotype: A meta-analysis of children-as-twins studies. Personality and Social Psychology Review, 18(1), 87-102.

*Bakker, J. M., Goossens, L., Kumar, P., Lange, I. M., Michielse, S., Schruers, K., ... \& Wichers, M. (2019). From laboratory to life: associating brain reward processing with real-life motivated behaviour and symptoms of depression in non-help-seeking young adults. Psychological Medicine, 49(14), 2441-2451.

*Bastiaansen, J. A., Bennik, E. C., Marsman, J. B. C., Ormel, J., Aleman, A., \& Oldehinkel, A. J. (2018). Prefrontal cortex activation during a cognitive reappraisal task is associated with real-life negative affect reactivity. PloS one, 13(8), e0202888.

Belkin, M. and Niyogi, P., 2003. Laplacian eigenmaps for dimensionality reduction and data representation. Neural Computation, 15(6), 1373-1396.

Berkman, E. T., \& Falk, E. B. (2013). Beyond brain mapping: Using neural measures to predict realworld outcomes. Current Directions in Psychological Science, 22(1), 45-50.

*Berkman, E. T., Falk, E. B., \& Lieberman, M. D. (2011). In the trenches of real-world self-control: neural correlates of breaking the link between craving and smoking. Psychological science, 22(4), 498-506.

*Blaine, S. K., Wemm, S., Fogelman, N., Lacadie, C., Seo, D., Scheinost, D., \& Sinha, R. (2020). Association of prefrontal-striatal functional pathology with alcohol abstinence days at treatment 

initiation and heavy drinking after treatment initiation. American Journal of Psychiatry, 177(11), 1048-1059.

Bolger, N., \& Laurenceau, J. P. (2013). Intensive longitudinal methods: An introduction to diary and experience sampling research. Guilford Press.

*Bourne, C., Mackay, C. E., \& Holmes, E. A. (2013). The neural basis of flashback formation: the impact of viewing trauma. Psychological Medicine, 43(7), 1521-1532.

*Butterfield, R. D., Siegle, G. J., Lee, K. H., Ladouceur, C. D., Forbes, E. E., Dahl, R. E., Ryan, N. D., Sheeber, L., \& Silk, J. S. (2019). Parental coping socialization is associated with healthy and anxious early adolescents' neural and real world response to threat. Developmental Science, 22(6), e12812.

Camacho, E., Brady Jr, R. O., Lizano, P., Keshavan, M., \& Torous, J. (2021). Advancing Translational Research Through the Interface of Digital Phenotyping and Neuroimaging: A Narrative Review. Biomarkers in Neuropsychiatry, 100032.

*Chen, P. H. A., Kelley, W. M., Lopez, R. B., \& Heatherton, T. F. (2019). Reducing reward responsivity and daily food desires in female dieters through domain-specific training. Social Neuroscience, 14(4), 470-483.

*Chester, D. S., \& DeWall, C. N. (2014). Prefrontal recruitment during social rejection predicts greater subsequent self-regulatory imbalance and impairment: neural and longitudinal evidence. NeuroImage, 101, 485-493.

474 Coifman, R.R. and Lafon, S., 2006. Diffusion maps. Applied and Computational Harmonic Analysis, 475 21(1), 5-30. 
476

477

478

479

480

481

482

483

484

485

486

487

488

489

490

491

492

493

494

495

496

*Collip, D., Habets, P., Marcelis, M., Gronenschild, E., Lataster, T., Lardinois, M., ... \& Myin-Germeys, I. (2013). Hippocampal volume as marker of daily life stress sensitivity in psychosis. Psychological Medicine, 43(7), 1377-1387.

*Culbreth, A. J., Moran, E. K., Kandala, S., Westbrook, A., \& Barch, D. M. (2020). Effort, avolition, and motivational experience in schizophrenia: Analysis of behavioral and neuroimaging data with relationships to daily motivational experience. Clinical Psychological Science, 8(3), 555-568.

*Dodell-Feder, D., DeLisi, L. E., \& Hooker, C. I. (2014). Neural disruption to theory of mind predicts daily social functioning in individuals at familial high-risk for schizophrenia. Social Cognitive and Affective Neuroscience, 9(12), 1914-1925.

*Dodell-Feder, D., Felix, S., Yung, M. G., \& Hooker, C. I. (2016). Theory-of-mind-related neural activity for one's romantic partner predicts partner well-being. Social Cognitive and Affective Neuroscience, 11(4), 593-603.

*Eisenberger, N. I., Gable, S. L., \& Lieberman, M. D. (2007a). Functional magnetic resonance imaging responses relate to differences in real-world social experience. Emotion, 7(4), 745.

*Eisenberger, N. I., Taylor, S. E., Gable, S. L., Hilmert, C. J., \& Lieberman, M. D. (2007b). Neural pathways link social support to attenuated neuroendocrine stress responses. Neuroimage, 35(4), 1601-1612.

Elliott, M. L., Knodt, A. R., Ireland, D., Morris, M. L., Poulton, R., Ramrakha, S., Sison, M. L., Moffitt, T. E., Caspi, A., \& Hariri, A. R. (2020). What is the test-retest reliability of common taskfunctional MRI measures? New empirical evidence and a meta-analysis. Psychological Science, 31(7), 792-806. 
497

498

499

500

501

502

503

504

505

506

507

508

509

510

511

512

513

514

515

516

517

518

*Fischer, S., Breithaupt, L., Wonderlich, J., Westwater, M. L., Crosby, R. D., Engel, S. G., ... \& Wonderlich, S. (2017). Impact of the neural correlates of stress and cue reactivity on stress related binge eating in the natural environment. Journal of Psychiatric Research, 92, 15-23.

*Flores, L. E., Eckstrand, K. L., Silk, J. S., Allen, N. B., Ambrosia, M., Healey, K. L., \& Forbes, E. E. (2018). Adolescents' neural response to social reward and real-world emotional closeness and positive affect. Cognitive, Affective, \& Behavioral Neuroscience, 18(4), 705-717.

*Forbes, E. E., Hariri, A. R., Martin, S. L., Silk, J. S., Moyles, D. L., Fisher, P. M., ... \& Dahl, R. E. (2009). Altered striatal activation predicting real-world positive affect in adolescent major depressive disorder. American Journal of Psychiatry, 166(1), 64-73.

*Forbes, E. E., Phillips, M. L., Silk, J. S., Ryan, N. D., \& Dahl, R. E. (2011). Neural systems of threat processing in adolescents: role of pubertal maturation and relation to measures of negative affect. Developmental Neuropsychology, 36(4), 429-452.

*Forbes, E. E., Ryan, N. D., Phillips, M. L., Manuck, S. B., Worthman, C. M., Moyles, D. L., ... \& Dahl, R. E. (2010). Healthy adolescents' neural response to reward: associations with puberty, positive affect, and depressive symptoms. Journal of the American Academy of Child \& Adolescent Psychiatry, 49(2), 162-172.

Gadassi Polack, R., Sened, H., Aubé, S., Zhang, A., Joormann, J., \& Kober, H. (in press). Connections during Crisis: Adolescents' social dynamics and mental health during COVID-19. Developmental Psychology.

*Giuliani, N. R., Tomiyama, A. J., Mann, T., \& Berkman, E. T. (2015). Prediction of daily food intake as a function of measurement modality and restriction status. Psychosomatic Medicine, 77(5), 583590. 
*Grosse Rueschkamp, J. M., Brose, A., Villringer, A., \& Gaebler, M. (2019). Neural correlates of upregulating positive emotions in fMRI and their link to affect in daily life. Social Cognitive and Affective Neuroscience, 14(10), 1049-1059.

*Habets, P., Collip, D., Myin-Germeys, I., Gronenschild, E., Van Bronswijk, S., Hofman, P., Lataster, T., Lardinois, M., Nicolson, N. A., van Os, J., \& Marcelis, M. (2012). Pituitary volume, stress reactivity and genetic risk for psychotic disorder. Psychological Medicine, 42(7), 1523-1533.

Hall, C. N., Howarth, C., Kurth-Nelson, Z., \& Mishra, A. (2016). Interpreting BOLD: towards a dialogue between cognitive and cellular neuroscience.

Hardoon, D.R., Szedmak, S. and Shawe-Taylor, J., 2004. Canonical correlation analysis: An overview with application to learning methods. Neural Computation, 16(12), 2639-2664.

*Hasler, B. P., Dahl, R. E., Holm, S. M., Jakubcak, J. L., Ryan, N. D., Silk, J. S., ... \& Forbes, E. E. (2012). Weekend-weekday advances in sleep timing are associated with altered reward-related brain function in healthy adolescents. Biological Psychology, 91(3), 334-341.

Hayes, A. F. (2017). Introduction to mediation, moderation, and conditional process analysis: A regression-based approach. Guilford publications.

*Heller, A. S., Fox, A. S., Wing, E. K., McQuisition, K. M., Vack, N. J., \& Davidson, R. J. (2015). The neurodynamics of affect in the laboratory predicts persistence of real-world emotional responses. Journal of Neuroscience, 35(29), 10503-10509.

*Heller, A. S., Shi, T. C., Ezie, C. C., Reneau, T. R., Baez, L. M., Gibbons, C. J., \& Hartley, C. A. (2020). Association between real-world experiential diversity and positive affect relates to hippocampal-striatal functional connectivity. Nature Neuroscience, 23(7), 800-804. 
540

541

542

543

544

545

546

547

548

549

550

551

552

553

554

555

556

557

558

559

560

561

562

*Holm, S. M., Forbes, E. E., Ryan, N. D., Phillips, M. L., Tarr, J. A., \& Dahl, R. E. (2009). Rewardrelated brain function and sleep in pre/early pubertal and mid/late pubertal adolescents. Journal of Adolescent Health, 45(4), 326-334.

*Hooker, C. I., Benson, T. L., Gyurak, A., Yin, H., Tully, L. M., \& Lincoln, S. H. (2014). Neural activity to positive expressions predicts daily experience of schizophrenia-spectrum symptoms in adults with high social anhedonia. Journal of Abnormal Psychology, 123(1), 190.

*Hooker, C. I., Gyurak, A., Verosky, S. C., Miyakawa, A., \& Ayduk, Ö. (2010). Neural activity to a partner's facial expression predicts self-regulation after conflict. Biological Psychiatry, 67(5), 406-413.

*Hua, J. P., Trull, T. J., Merrill, A. M., McCarty, R. M., Straub, K. T., \& Kerns, J. G. (2020). Daily-life affective instability in emotional distress disorders is associated with function and structure of posterior parietal cortex. Psychiatry Research: Neuroimaging, 296, 111028.

*Ismaylova, E., Di Sante, J., Gouin, J. P., Pomares, F. B., Vitaro, F., Tremblay, R. E., \& Booij, L. (2018). Associations between daily mood states and brain gray matter volume, resting-state functional connectivity and task-based activity in healthy adults. Frontiers in Human Neuroscience, 12, 168.

James, G., Witten, D., Hastie, T., \& Tibshirani, R. (2013). An introduction to statistical learning (Vol. 112, p. 18). New York: springer.

*Kaiser, R. H., Peterson, E., Kang, M. S., Van Der Feen, J., Aguirre, B., Clegg, R., ... \& Pizzagalli, D. A. (2019). Frontoinsular network markers of current and future adolescent mood health. Biological Psychiatry: Cognitive Neuroscience and Neuroimaging, 4(8), 715-725.

*Kashdan, T. B., DeWall, C. N., Masten, C. L., Pond Jr, R. S., Powell, C., Combs, D., ... \& Farmer, A. S. (2014). Who is most vulnerable to social rejection? The toxic combination of low self-esteem and lack of negative emotion differentiation on neural responses to rejection. PLoS One, 9(3), e90651. 
*Kluge, A., Kirschner, M., Hager, O. M., Bischof, M., Habermeyer, B., Seifritz, E., ... \& Kaiser, S. (2018). Combining actigraphy, ecological momentary assessment and neuroimaging to study apathy in patients with schizophrenia. Schizophrenia Research, 195, 176-182.

Kohavi, R. and John, G.H., 1997. Wrappers for feature subset selection. Artificial intelligence, 97(1-2), 273-324.

*Krönke, K. M., Wolff, M., Shi, Y., Kräplin, A., Smolka, M. N., Bühringer, G., \& Goschke, T. (2020). Functional connectivity in a triple-network saliency model is associated with real-life selfcontrol. Neuropsychologia, 149, 107667.

*Krönke, K. M., Wolff, M., Mohr, H., Kräplin, A., Smolka, M. N., Bühringer, G., \& Goschke, T. (2018). Monitor yourself! Deficient error-related brain activity predicts real-life self-control failures. Cognitive, Affective, \& Behavioral Neuroscience, 18(4), 622-637.

*Lee, T. H., Miernicki, M. E., \& Telzer, E. H. (2017a). Behavioral and neural concordance in parent-child dyadic sleep patterns. Developmental Cognitive Neuroscience, 26, 77-83.

*Lee, T. H., Miernicki, M. E., \& Telzer, E. H. (2017b). Families that fire together smile together: Resting state connectome similarity and daily emotional synchrony in parent-child dyads. NeuroImage, 152, 31-37.

Liberati, A., Altman, D. G., Tetzlaff, J., Mulrow, C., Gøtzsche, P. C., Ioannidis, J. P., ... \& Moher, D. (2009). The PRISMA statement for reporting systematic reviews and meta-analyses of studies that evaluate health care interventions: explanation and elaboration. Journal of Clinical Epidemiology, 62(10), e1-e34.

Lindenbaum, O., Yeredor, A., Salhov, M. and Averbuch, A., 2020. Multi-view diffusion maps. Information Fusion, 55, 127-149. 
585

586

587

588

589

590

591

592

593

594

595

596

597

598

599

600

601

602

603

604

605

606

607

Logothetis, N. K. (2008). What we can do and what we cannot do with fMRI. Nature, 453(7197), 869878.

*Lopez, R. B., Chen, P. H. A., Huckins, J. F., Hofmann, W., Kelley, W. M., \& Heatherton, T. F. (2017). A balance of activity in brain control and reward systems predicts self-regulatory outcomes. Social Cognitive and Affective Neuroscience, 12(5), 832-838.

*Lopez, R. B., Hofmann, W., Wagner, D. D., Kelley, W. M., \& Heatherton, T. F. (2014). Neural predictors of giving in to temptation in daily life. Psychological Science, 25(7), 1337-1344.

*Lopez, R. B., Milyavskaya, M., Hofmann, W., \& Heatherton, T. F. (2016). Motivational and neural correlates of self-control of eating: a combined neuroimaging and experience sampling study in dieting female college students. Appetite, 103, 192-199.

*Martin-Soelch, C., Guillod, M., Gaillard, C., Recabarren, R. E., Federspiel, A., Mueller-Pfeiffer, C., ... \& Gomez, P. (2020). Increased reward-related activation in the ventral striatum during stress exposure associated with positive affect in the daily life of young adults with a family history of depression: Preliminary findings. Frontiers in Psychiatry, 11.

*Masten, C. L., Telzer, E. H., Fuligni, A. J., Lieberman, M. D., \& Eisenberger, N. I. (2012). Time spent with friends in adolescence relates to less neural sensitivity to later peer rejection. Social Cognitive and Affective Neuroscience, 7(1), 106-114.

Mather, M., Cacioppo, J. T., \& Kanwisher, N. (2013). How fMRI can inform cognitive theories. Perspectives on Psychological Science, 8(1), 108-113.

Mauss, I. B., \& Robinson, M. D. (2009). Measures of emotion: A review. Cognition and Emotion, 23(2), 209-237.

Michaeli, T., Wang, W. and Livescu, K., 2016, June. Nonparametric canonical correlation analysis. In International conference on machine learning (pp. 1967-1976). PMLR. 
608

609

610

611

612

613

614

615

616

617

618

619

620

621

622

623

624

625

626

627

628

629

Mischel, W., \& Shoda, Y. (1995). A cognitive-affective system theory of personality: reconceptualizing situations, dispositions, dynamics, and invariance in personality structure. Psychological Review, 102(2), 246-268.

*Moran, E. K., Culbreth, A. J., Kandala, S., \& Barch, D. M. (2019). From neuroimaging to daily functioning: A multimethod analysis of reward anticipation in people with schizophrenia. Journal of Abnormal Psychology, 128(7), 723-734.

*Morelli, S. A., Rameson, L. T., \& Lieberman, M. D. (2014). The neural components of empathy: predicting daily prosocial behavior. Social Cognitive and Affective Neuroscience, 9(1), 39-47.

*Nook, E. C., Dodell-Feder, D., Germine, L. T., Hooley, J. M., DeLisi, L. E., \& Hooker, C. I. (2018). Weak dorsolateral prefrontal response to social criticism predicts worsened mood and symptoms following social conflict in people at familial risk for schizophrenia. NeuroImage: Clinical, 18, $40-50$.

*Olino, T. M., McMakin, D. L., Morgan, J. K., Silk, J. S., Birmaher, B., Axelson, D. A., ... \& Forbes, E. E. (2014). Reduced reward anticipation in youth at high-risk for unipolar depression: a preliminary study. Developmental Cognitive Neuroscience, 8, 55-64.

*Oppenheimer, C. W., Silk, J. S., Lee, K. H., Dahl, R. E., Forbes, E., Ryan, N., \& Ladouceur, C. D. (2020). Suicidal ideation among anxious youth: a preliminary investigation of the role of neural processing of social rejection in interaction with real world negative social experiences. Child Psychiatry \& Human Development, 51(2), 163-173.

*Pace-Schott, E. F., Zimmerman, J. P., Bottary, R. M., Lee, E. G., Milad, M. R., \& Camprodon, J. A. (2017). Resting state functional connectivity in primary insomnia, generalized anxiety disorder and controls. Psychiatry Research: Neuroimaging, 265, 26-34. 
630

631

632

633

634

635

636

637

638

639

640

641

642

643

644

645

646

647

648

649

650

651

652

Park, T. and Casella, G., 2008. The bayesian lasso. Journal of the American Statistical Association, 103(482), 681-686.

Poldrack, R. A. (2011). Inferring mental states from neuroimaging data: from reverse inference to largescale decoding. Neuron, 72(5), 692-697.

*Powers, K. E., Chavez, R. S., \& Heatherton, T. F. (2016). Individual differences in response of dorsomedial prefrontal cortex predict daily social behavior. Social Cognitive and Affective Neuroscience, 11(1), 121-126.

*Price, R. B., Allen, K. B., Silk, J. S., Ladouceur, C. D., Ryan, N. D., Dahl, R. E., ... \& Siegle, G. J. (2016). Vigilance in the laboratory predicts avoidance in the real world: A dimensional analysis of neural, behavioral, and ecological momentary data in anxious youth. Developmental Cognitive Neuroscience, 19, 128-136.

*Provenzano, J., Bastiaansen, J. A., Verduyn, P., Oldehinkel, A. J., Fossati, P., \& Kuppens, P. (2018). Different aspects of the neural response to socio-emotional events are related to instability and inertia of emotional experience in daily life: an fMRI-ESM study. Frontiers in Human Neuroscience, 12, 501.

*Rahdar, A., \& Galván, A. (2014). The cognitive and neurobiological effects of daily stress in adolescents. NeuroImage, 92, 267-273.

*Rameson, L. T., Morelli, S. A., \& Lieberman, M. D. (2012). The neural correlates of empathy: experience, automaticity, and prosocial behavior. Journal of Cognitive Neuroscience, 24(1), 235245.

*Rattel, J. A., Miedl, S. F., Franke, L. K., Grünberger, L. M., Blechert, J., Kronbichler, M., ... \& Wilhelm, F. H. (2019). Peritraumatic neural processing and intrusive memories: the role of lifetime adversity. Biological Psychiatry: Cognitive Neuroscience and Neuroimaging, 4(4), 381-389. 
Russell, M. A., \& Gajos, J. M. (2020). Annual Research Review: Ecological momentary assessment studies in child psychology and psychiatry. Journal of Child Psychology and Psychiatry, 61(3), 376-394.

*Scholz, C., Doré, B. P., Cooper, N., \& Falk, E. B. (2019). Neural valuation of antidrinking campaigns and risky peer influence in daily life. Health Psychology, 38(7), 658-667.

*Schwartz, J., Ordaz, S. J., Kircanski, K., Ho, T. C., Davis, E. G., Camacho, M. C., \& Gotlib, I. H. (2019). Resting-state functional connectivity and inflexibility of daily emotions in major depression. Journal of Affective Disorders, 249, 26-34.

*Seidel, M., King, J. A., Ritschel, F., Boehm, I., Geisler, D., Bernardoni, F., Holzapfel, L., Diestel, S., Diers, K., Strobel, A., Goschke, T., Walter, H., Roessner, V., \& Ehrlich, S. (2018). The real-life costs of emotion regulation in anorexia nervosa: a combined ecological momentary assessment and fMRI study. Translational Psychiatry, 8(1), 1-11.

*Servaas, M. N., Riese, H., Renken, R. J., Wichers, M., Bastiaansen, J. A., Figueroa, C. A., ... \& Ruhé, H. G. (2017). Associations between daily affective instability and connectomics in functional subnetworks in remitted patients with recurrent major depressive disorder. Neuropsychopharmacology, 42(13), 2583-2592.

Shamay-Tsoory, S. G., \& Mendelsohn, A. (2019). Real-life neuroscience: an ecological approach to brain and behavior research. Perspectives on Psychological Science, 14(5), 841-859.

Shimamura, A. P. (2010). Bridging psychological and biological science: The good, bad, and ugly. Perspectives on Psychological Science, 5(6), 772-775.

Schölkopf, B., Smola, A. and Müller, K.R., 1998. Nonlinear component analysis as a kernel eigenvalue problem. Neural Computation, 10(5), 1299-1319. 
675 Shrout, P. E., Bolger, N., Iida, M., Burke, C., Gleason, M. E., \& Lane, S. P. (2010). The effects of daily

676

677

678

679

680

681

682

683

684

685

686

687

688

689

690

691

692

693

694

695

696

support transactions during acute stress: Results from a diary study of bar exam preparation. Support processes in intimate relationships, 175-199.

Snir, A., Rafaeli, E., Gadassi, R., Berenson, K., \& Downey, G. (2015). Explicit and inferred motives for nonsuicidal self-injurious acts and urges in borderline and avoidant personality disorders. Personality Disorders: Theory, Research, and Treatment, 6(3), 267.

Stange, J. P., Kleiman, E. M., Mermelstein, R. J., \& Trull, T. J. (2019). Using ambulatory assessment to measure dynamic risk processes in affective disorders. Journal of Affective Disorders, 259, 325336.

*Telzer, E. H., Fuligni, A. J., Lieberman, M. D., Miernicki, M. E., \& Galván, A. (2015). The quality of adolescents' peer relationships modulates neural sensitivity to risk taking. Social Cognitive and Affective Neuroscience, 10(3), 389-398.

*Tost, H., Reichert, M., Braun, U., Reinhard, I., Peters, R., Lautenbach, S., Hoell, A., Schwarz, E., EbnerPriemer, U., Zipf, A., \& Meyer-Lindenberg, A. (2019). Neural correlates of individual differences in affective benefit of real-life urban green space exposure. Nature Neuroscience, 22(9), 13891393.

Trull, T. J., \& Ebner-Priemer, U. W. (2020). Ambulatory assessment in psychopathology research: A review of recommended reporting guidelines and current practices. Journal of Abnormal Psychology, 129(1), 56-63.

*Tully, L. M., Lincoln, S. H., \& Hooker, C. I. (2014). Lateral prefrontal cortex activity during cognitive control of emotion predicts response to social stress in schizophrenia. NeuroImage: Clinical, 6, 43-53. 
697

698

699

700

701

702

703

704

705

706

707

708

709

710

711

712

713

714

715

716

717

*Uy, J. P., \& Galván, A. (2017a). Acute stress increases risky decisions and dampens prefrontal activation among adolescent boys. NeuroImage, 146, 679-689.

*Uy, J. P., \& Galván, A. (2017b). Sleep duration moderates the association between insula activation and risky decisions under stress in adolescents and adults. Neuropsychologia, 95, 119-129.

*Uy, J. P., \& Galván, A. (2020). Individual differences in accumbofrontal tract integrity relate to risky decisions under stress in adolescents and adults. Developmental Cognitive Neuroscience, 100859.

*Vekaria, K. M., O'Connell, K., Rhoads, S. A., Brethel-Haurwitz, K. M., Cardinale, E. M., Robertson, E. L., Walitt, B.,VanMeter, J. W., \& Marsh, A. A. (2020). Activation in bed nucleus of the stria terminalis (BNST) corresponds to everyday helping. Cortex, 127, 67-77.

*Waugh, C. E., Shing, E. Z., Avery, B. M., Jung, Y., Whitlow, C. T., \& Maldjian, J. A. (2017). Neural predictors of emotional inertia in daily life. Social Cognitive and Affective Neuroscience, 12(9), $1448-1459$.

Wilson, S. J., Smyth, J. M., \& MacLean, R. R. (2013). Integrating ecological momentary assessment and functional brain imaging methods: new avenues for studying and treating tobacco dependence. Nicotine \& Tobacco Research, 16(Suppl_2), S102-S110.

*Winkelman, J. W., Plante, D. T., Schoerning, L., Benson, K., Buxton, O. M., O'Connor, S. P., ... \& Gonenc, A. (2013). Increased rostral anterior cingulate cortex volume in chronic primary insomnia. Sleep, 36(7), 991-998.

*Wonderlich, J. A., Breithaupt, L. E., Crosby, R. D., Thompson, J. C., Engel, S. G., \& Fischer, S. (2017). The relation between craving and binge eating: Integrating neuroimaging and ecological momentary assessment. Appetite, 117, 294-302. 
718 *Wonderlich, J. A., Breithaupt, L., Thompson, J. C., Crosby, R. D., Engel, S. G., \& Fischer, S. (2018).

719 The impact of neural responses to food cues following stress on trajectories of negative and 720 positive affect and binge eating in daily life. Journal of Psychiatric Research, 102, 14-22.

721 *Woods, B. K., Forbes, E. E., Sheeber, L. B., Allen, N. B., Silk, J. S., Jones, N. P., \& Morgan, J. K.

722 (2020). Positive affect between close friends: Brain-behavior associations during

723 adolescence. Social Neuroscience, 15(2), 128-139.

724 Yamada, Y., Lindenbaum, O., Negahban, S. and Kluger, Y., 2020, November. Feature selection using 725 stochastic gates. In International Conference on Machine Learning (pp. 10648-10659). PMLR.

726 Zou, H. and Hastie, T., 2005. Regularization and variable selection via the elastic net. Journal of the royal 727 statistical society: series B (statistical methodology), 67(2), 301-320. 


\section{Table 1}

Summary of 71 Studies that Combine MRI/fMRI and EMA, 2007-2020, in chronological order by year of publication.

\begin{tabular}{|c|c|c|c|c|c|c|c|c|c|c|}
\hline Study $^{\mathrm{a}}$ & Authors ${ }^{b}$ & Citations per Year ${ }^{\mathrm{C}}$ & $\mathrm{IF}^{\mathrm{d}}$ & Study population ${ }^{\mathrm{e}}$ & $\begin{array}{l}\text { Sample } \\
\text { Size }\end{array}$ & Compensation $^{\mathrm{g}}$ & $\begin{array}{l}\text { EMA assessments } \\
\text { (Prompts/Days) }^{\text {h }}\end{array}$ & EMA constructs & MRI constructs & Method order \\
\hline $\begin{array}{l}\text { Eisenberger et } \\
\text { al. (2007) }\end{array}$ & 3 & 11.93 & 4.329 & $\begin{array}{c}\text { Non-clinical; adults, } \\
\text { age }=20.7^{i}\end{array}$ & 30 & - & $80 / 10$ & Social interactions, affect & Social & EMA before MRI \\
\hline $\begin{array}{l}\text { Eisenberger et } \\
\text { al. (2007) }\end{array}$ & 5 & 36.64 & 6.556 & $\begin{array}{l}\text { Non-clinical; adults, age=18- } \\
36\end{array}$ & 30 & 60 & $80 / 10$ & Social interactions, affect & Social & EMA before MRI \\
\hline $\begin{array}{l}\text { Forbes et al. } \\
\text { (2009) }\end{array}$ & 11 & 45.42 & 18.112 & $\begin{array}{l}\text { Clinical depression; } \\
\text { adolescents, age=8-17 }\end{array}$ & 43 & 75 & $12 / 4$ & Social interactions, affect & Reward processing & EMA before MRI \\
\hline $\begin{array}{l}\text { Holm et al. } \\
\text { (2009) }\end{array}$ & 6 & 12.42 & 5.012 & $\begin{array}{l}\text { Non-clinical; adolescents, } \\
\text { age }=11-13\end{array}$ & 58 & - & $\mathrm{NA} / 4^{\mathrm{m}}$ & Sleep & Reward processing & Varied \\
\hline $\begin{array}{l}\text { Forbes et al. } \\
\text { (2010) }\end{array}$ & 9 & 28.09 & 8.829 & $\begin{array}{c}\text { Non-clinical; adolescents, } \\
\text { age }=11-13\end{array}$ & 77 & - & $12 / 4$ & Social interactions, affect & Reward processing & Varied \\
\hline $\begin{array}{l}\text { Hooker et al. } \\
\text { (2010) }\end{array}$ & 5 & 5.55 & 13.382 & $\begin{array}{c}\text { Non-clinical; adults in } \\
\text { committed relationships; } \\
\qquad \text { age }=21^{\mathrm{i}}\end{array}$ & 27 & - & $21 / 21$ & $\begin{array}{l}\text { Social interactions, affect, } \\
\text { substance use }\end{array}$ & Social & - \\
\hline $\begin{array}{l}\text { Berkman et al. } \\
\text { (2011) }\end{array}$ & 3 & 20.30 & 7.029 & $\begin{array}{l}\text { Heavy cigarette smokers; } \\
\text { adults, age=28-69 }\end{array}$ & 27 & 248 & $168 / 21$ & $\begin{array}{l}\text { Affect, substance use, } \\
\text { craving }\end{array}$ & Regulation/inhibition & MRI before EMA \\
\hline $\begin{array}{l}\text { Forbes et al. } \\
\text { (2011) }\end{array}$ & 4 & 12.30 & 2.253 & $\begin{array}{c}\text { Non-clinical; adolescents, } \\
\text { age }=11-13\end{array}$ & 76 & - & $12 / 4$ & Affect & Emotion processing & Varied \\
\hline $\begin{array}{l}\text { Habets et al. } \\
\text { (2012) }\end{array}$ & 11 & 5.33 & 7.723 & $\begin{array}{l}\text { Psychotic disorders; } \\
\text { adolescents and adults, } \\
\text { age }=16-55\end{array}$ & 89 & - & $60 / 6$ & Social interactions, affect & Structural/DTI & EMA before MRI \\
\hline $\begin{array}{l}\text { Hasler et al. } \\
\text { (2012) }\end{array}$ & 8 & 12.56 & 13.382 & $\begin{array}{l}\text { Non-clinical; adolescents, } \\
\text { age }=11-13\end{array}$ & 56 & - & $12 / 4$ & Affect & Reward processing & Varied \\
\hline $\begin{array}{l}\text { Masten et al. } \\
\text { (2012) }\end{array}$ & 5 & 20.56 & 3.436 & $\begin{array}{l}\text { Non-clinical; adolescents, } \\
\text { mean age }=17.77\end{array}$ & 21 & N.A. & $14 / 14$ & Social interactions & Social & EMA before MRI \\
\hline $\begin{array}{l}\text { Rameson et al. } \\
\text { (2012) }\end{array}$ & 3 & 31.56 & 3.225 & Non-clinical; adults, age $=19^{\mathrm{i}}$ & 32 & - & $14 / 14$ & Social interactions & Social & EMA before MRI \\
\hline $\begin{array}{l}\text { Bourne et al. } \\
\text { (2013) }\end{array}$ & 3 & 14.88 & 7.723 & Non-clinical; adults, age $=22^{\mathrm{i}}$ & 22 & - & $6.82 / 7$ & $\begin{array}{l}\text { Psychopathology } \\
\text { symptoms }\end{array}$ & Emotion processing & MRI before EMA \\
\hline
\end{tabular}




\begin{tabular}{|c|c|c|c|c|c|}
\hline $\begin{array}{l}\text { Collip et al. } \\
\text { (2013) }\end{array}$ & 8 & 6.25 & 7.723 & $\begin{array}{c}\text { Psychotic disorders; } \\
\text { adolescents and adults, } \\
\text { age }=16-55\end{array}$ & 89 \\
\hline $\begin{array}{l}\text { Winkleman et } \\
\text { al. (2013) }\end{array}$ & 9 & 13.13 & 5.849 & $\begin{array}{c}\text { Primary insomnia; adults, } \\
\text { age }=18-60\end{array}$ & 76 \\
\hline $\begin{array}{l}\text { Chester \& } \\
\text { DeWall (2014) }\end{array}$ & 2 & 5.00 & 6.556 & $\begin{array}{c}\text { Non-clinical; adults; mean } \\
\text { age }=18.92^{i}\end{array}$ & 37 \\
\hline $\begin{array}{l}\text { Dodell-Feder } \\
\text { et al. (2014) }\end{array}$ & 3 & 4.86 & 3.436 & $\begin{array}{l}\text { At-risk for schizophrenia; } \\
\text { adolescents and adults, } \\
\text { age }=15-32\end{array}$ & 32 \\
\hline $\begin{array}{l}\text { Hooker et al. } \\
\text { (2014) }\end{array}$ & 6 & 7.14 & 6.673 & $\begin{array}{l}\text { Non-clinical; adults, age }=19- \\
52\end{array}$ & 30 \\
\hline $\begin{array}{l}\text { Kashdan et al. } \\
\text { (2014) }\end{array}$ & 8 & 6.57 & 3.240 & $\begin{array}{c}\text { Non-clinical; adults, } \\
\text { age }=20.9^{\mathrm{i}}\end{array}$ & 25 \\
\hline $\begin{array}{l}\text { Lopez et al. } \\
\text { (2014) }\end{array}$ & 5 & 22.29 & 7.029 & $\begin{array}{l}\text { Non-clinical; adults, age }=18- \\
28\end{array}$ & 28 \\
\hline $\begin{array}{l}\text { Morelli et al. } \\
\text { (2014) }\end{array}$ & 3 & 40.86 & 3.436 & $\begin{array}{c}\text { Non-clinical; adults, } \\
\text { age }=19.9^{\mathrm{i}}\end{array}$ & 32 \\
\hline $\begin{array}{l}\text { Olino et al. } \\
\text { (2014) }\end{array}$ & 10 & 16.14 & 6.464 & $\begin{array}{c}\text { At-risk for depression; } \\
\text { children and adolescents, } \\
\text { age }=8-17\end{array}$ & 26 \\
\hline $\begin{array}{l}\text { Rahdar \& } \\
\text { Galvan (2014) }\end{array}$ & 2 & 9.00 & 6.556 & $\begin{array}{l}\text { Non-clinical; adolescents } \\
\text { and adults, age }=15-30\end{array}$ & 45 \\
\hline $\begin{array}{l}\text { Tully et al. } \\
\text { (2014) }\end{array}$ & 3 & 5.29 & 4.881 & $\begin{array}{c}\text { Schizophrenia; adults, } \\
\text { age }=18-65\end{array}$ & 47 \\
\hline $\begin{array}{l}\text { Giuliani et al. } \\
\text { (2015) }\end{array}$ & 4 & 1.17 & 4.312 & $\begin{array}{c}\text { Non-clinical (food restriction } \\
\text { intervention) }{ }^{\mathrm{j}} \text {; adults, } \\
\text { age }=18-30\end{array}$ & 46 \\
\hline $\begin{array}{l}\text { Heller et al. } \\
\text { (2015) }\end{array}$ & 6 & 7.83 & 6.167 & $\begin{array}{l}\text { Non-clinical; adults, age }=18- \\
24\end{array}$ & 40 \\
\hline
\end{tabular}

$60 / 6$

Social interactions, affect

Structural/DTI

N.A.

Sleep

N.A.,

course credit

N.A.

$28 / 28$

N.A.

50

N.A.

cial interactions, affect,

$$
24
$$

$14 / 14$

$21 / 21$

$21 / 21$

$49 / 7$

$14 / 14$

$12 / 4$

$42 / 14$

$21 / 21$ substance use, selfregulation

Social interactions, affect regulation/inhibition

EMA before MRI

Social

MRI before EMA

$$
\begin{gathered}
\text { Affect, } \\
\text { psychopatholog } \\
\text { symptoms }
\end{gathered}
$$

Social

Social interactions, affect,

Social self-esteem

Craving

Regulation/inhibition

Social interactions

Social

Affect

Affect

Affect, psychopathology symptoms

$56 / 14$

Craving

$250 / 10$
MRIs during EMA period

MRI before EMA

MRI before EMA

EMA before MRI 


\begin{tabular}{|c|c|c|c|c|c|}
\hline $\begin{array}{l}\text { Telzer et al. } \\
\text { (2015) }\end{array}$ & 5 & 21.83 & 3.436 & $\begin{array}{c}\text { Non-clinical; adolescents, } \\
\text { age }=14-17\end{array}$ & 46 \\
\hline $\begin{array}{l}\text { Dodell-Feder } \\
\text { et al. (2016) }\end{array}$ & 4 & 2.80 & 3.436 & $\begin{array}{c}\text { Non-clinical; adults in } \\
\text { committed relationships, } \\
\text { age =18-35 }\end{array}$ & 22 \\
\hline $\begin{array}{l}\text { Lopez et al. } \\
\text { (2016) }\end{array}$ & 4 & 7.80 & 3.868 & $\begin{array}{c}\text { Non-clinical (chronic } \\
\text { dieters) }{ }^{\mathrm{j}} \text {; adults, age=18-23 }\end{array}$ & 69 \\
\hline $\begin{array}{l}\text { Powers et al. } \\
\text { (2016) }\end{array}$ & 3 & 6.20 & 3.436 & $\begin{array}{l}\text { Non-clinical; adults, age }=18- \\
21\end{array}$ & 33 \\
\hline $\begin{array}{l}\text { Price et al. } \\
\text { (2016) }\end{array}$ & 8 & 7.60 & 6.464 & $\begin{array}{l}\text { Clinical anxiety; children } \\
\text { and adolescents, age=9-14 }\end{array}$ & 78 \\
\hline $\begin{array}{l}\text { Fischer et al. } \\
\text { (2017) }\end{array}$ & 9 & 8.50 & 4.791 & $\begin{array}{c}\text { Bulimia nervosa and } \\
\text { EDNOS; adults, age }=18-40\end{array}$ & 16 \\
\hline $\begin{array}{l}\text { Lee et al. } \\
\text { (2017) }\end{array}$ & 3 & 1.00 & 6.464 & $\begin{array}{l}\text { Non-clinical; adolescents } \\
\text { and caregivers, age }=13-57\end{array}$ & 53 \\
\hline $\begin{array}{l}\text { Lee et al. } \\
\text { (2017) }\end{array}$ & 3 & 10.25 & 6.556 & $\begin{array}{l}\text { Non-clinical; adolescents } \\
\text { and caregivers, age }=13-57\end{array}$ & 53 \\
\hline $\begin{array}{l}\text { Lopez et al. } \\
\text { (2017) }\end{array}$ & 6 & 8.75 & 3.436 & $\begin{array}{c}\text { Non-clinical (chronic } \\
\text { dieters); } \text {; adults, age=18-23 }\end{array}$ & 69 \\
\hline $\begin{array}{l}\text { Pace-Schott et } \\
\text { al. (2017) }\end{array}$ & 6 & 7.00 & 2.376 & $\begin{array}{c}\text { Primary insomnia; adults, } \\
\text { age }=\text { mid-30s }\end{array}$ & 26 \\
\hline $\begin{array}{l}\text { Servaas et al. } \\
\text { (2017) }\end{array}$ & 14 & 5.00 & 7.853 & $\begin{array}{l}\text { Remitted clinical depression; } \\
\text { adults, age=mid-50s }\end{array}$ & 69 \\
\hline $\begin{array}{l}\text { Uy \& Galvan } \\
\text { (2017) }\end{array}$ & 2 & 5.50 & 6.556 & $\begin{array}{l}\text { Non-clinical; adolescents } \\
\text { and adults, age }=15-30\end{array}$ & 45 \\
\hline $\begin{array}{l}\text { Uy \& Galvan } \\
\text { (2017) }\end{array}$ & 2 & 5.50 & 3.139 & $\begin{array}{l}\text { Non-clinical; adolescents } \\
\text { and adults, age }=15-30\end{array}$ & 44 \\
\hline $\begin{array}{l}\text { Waugh et al. } \\
\text { (2017) }\end{array}$ & 6 & 4.00 & 3.436 & $\begin{array}{l}\text { Non-clinical; adults, age }=21- \\
65\end{array}$ & 29 \\
\hline $\begin{array}{l}\text { Wonderlich et } \\
\text { al. (2017) }\end{array}$ & 6 & 5.50 & 3.868 & $\begin{array}{l}\text { Bulimia nervosa; adults, } \\
\text { age }=18-40\end{array}$ & 16 \\
\hline
\end{tabular}

\begin{tabular}{|c|c|c|c|c|}
\hline N.A. & $28 / 28$ & Social interactions & Risk-taking & EMA before MRI \\
\hline N.A. & $21 / 21$ & $\begin{array}{l}\text { Social interactions, affect, } \\
\text { self-esteem }\end{array}$ & Social & MRI before EMA \\
\hline- & $49 / 7$ & Craving & Regulation/inhibition & MRI before EMA \\
\hline N.A. & $49 / 7$ & Social interactions & $\begin{array}{l}\text { Social, emotion } \\
\text { processing }\end{array}$ & MRI before EMA \\
\hline- & $14 / 5$ & $\begin{array}{l}\text { Affect, psychopathology } \\
\text { symptoms }\end{array}$ & Emotion processing & MRI before EMA \\
\hline N.A. & $98 / 14$ & $\begin{array}{l}\text { Affect, craving, } \\
\text { psychopathology } \\
\text { symptoms }\end{array}$ & Regulation/inhibition & MRI before EMA \\
\hline- & $14 / 14$ & Sleep & Resting state & - \\
\hline- & $14 / 14$ & Affect & Resting state & MRI before EMA \\
\hline- & $49 / 7$ & Craving & Regulation/inhibition & MRI before EMA \\
\hline- & $14 / 14$ & Sleep & Resting state & EMA before MRI \\
\hline- & $60 / 6$ & $\begin{array}{l}\text { Social interactions, affect, } \\
\text { self-esteem }\end{array}$ & Resting state & EMA before MRI \\
\hline N.A. & $42 / 14$ & Affect & Risk-taking & $\begin{array}{l}\text { MRIs during EMA } \\
\text { period }\end{array}$ \\
\hline N.A. & $42 / 14$ & Affect & Risk-taking & $\begin{array}{l}\text { MRIs during EMA } \\
\text { period }\end{array}$ \\
\hline 60 & $7 / 7$ & Affect & Social & MRI before EMA \\
\hline 350 & $98 / 14$ & $\begin{array}{l}\text { Affect, craving, } \\
\text { psychopathology } \\
\text { symptoms }\end{array}$ & Regulation/inhibition & MRI before EMA \\
\hline
\end{tabular}




\begin{tabular}{|c|c|c|c|c|c|c|c|}
\hline $\begin{array}{l}\text { Bastiaansen et } \\
\text { al. (2018) }\end{array}$ & 6 & 1.00 & 3.240 & $\begin{array}{l}\text { Non-clinical }{ }^{\mathrm{k}} \text {; adults, } \\
\text { age }=18-25^{2}\end{array}$ & 69 & N.A. & $70 / 14$ \\
\hline $\begin{array}{l}\text { Chen et al. } \\
\text { (2018) }\end{array}$ & 4 & 2.00 & 2.083 & $\begin{array}{c}\text { Non-clinical (chronic } \\
\text { dieters); } \text {; adults, age }=19{ }^{\mathrm{i}}\end{array}$ & 36 & - & $98 / 14^{\mathrm{r}}$ \\
\hline $\begin{array}{l}\text { Flores et al. } \\
\text { (2018) }\end{array}$ & 7 & 3.33 & 3.282 & $\begin{array}{c}\text { Non-clinical; adolescents, } \\
\text { age }=14-18\end{array}$ & 33 & - & $28 / 10$ \\
\hline $\begin{array}{l}\text { Ismaylova et } \\
\text { al. (2018) }\end{array}$ & 7 & 3.67 & 3.169 & $\begin{array}{l}\text { Non-clinical; adults, age }=32- \\
36\end{array}$ & 42 & - & $5 / 5$ \\
\hline $\begin{array}{l}\text { Kluge et al. } \\
\text { (2018) }\end{array}$ & 8 & 11.00 & 4.939 & $\begin{array}{c}\text { Schizophrenia; adults, } \\
\text { age }=32^{\mathrm{i}}\end{array}$ & 18 & N.A. & $40 / 4$ \\
\hline $\begin{array}{l}\text { Kronke et al. } \\
\text { (2018) }\end{array}$ & 7 & 6.33 & 3.282 & $\begin{array}{l}\text { Non-clinical; adults, age }=20- \\
26\end{array}$ & 118 & 47 & $56 / 7$ \\
\hline $\begin{array}{l}\text { Nook et al. } \\
\text { (2018) }\end{array}$ & 6 & 2.33 & 4.881 & $\begin{array}{l}\text { At-risk for schizophrenia; } \\
\text { adolescents and adults, } \\
\text { age }=15-32\end{array}$ & 36 & - & $28 / 28$ \\
\hline $\begin{array}{l}\text { Provenzano et } \\
\text { al. (2018) }\end{array}$ & 6 & 0.67 & 3.169 & $\begin{array}{l}\text { Non-clinical }^{\mathrm{k}} \text {; adults, } \\
\text { age }=18-25\end{array}$ & 65 & - & $70 / 14$ \\
\hline $\begin{array}{l}\text { Seidel et al. } \\
\text { (2018) }\end{array}$ & 14 & 10.33 & 6.222 & $\begin{array}{c}\text { Anorexia nervosa; } \\
\text { adolescents and adults, } \\
\text { age=12-29 }\end{array}$ & 70 & - & $84 / 14$ \\
\hline $\begin{array}{l}\text { Wonderlich et } \\
\text { al. (2018) }\end{array}$ & 6 & 5.33 & 4.791 & $\begin{array}{c}\text { Bulimia nervosa; adults, } \\
\text { age }=18-40\end{array}$ & 16 & N.A. & $98 / 14$ \\
\hline $\begin{array}{l}\text { Bakker et al. } \\
\text { (2019) }\end{array}$ & 14 & 9.50 & 7.723 & $\begin{array}{l}\text { Clinical depression; } \\
\text { adolescents and adults, } \\
\text { age=16-25 }\end{array}$ & 87 & - & $150 / 15$ \\
\hline $\begin{array}{l}\text { Butterfield et } \\
\text { al. }(2019)^{(5)}\end{array}$ & 9 & 2.50 & 5.131 & $\begin{array}{l}\text { Clinical anxiety; children } \\
\text { and adolescents, age=9-14 }\end{array}$ & 120 & - & $14 / 5$ \\
\hline $\begin{array}{l}\text { Grosse- } \\
\text { Rueschkamp } \\
\text { et al. (2019) }\end{array}$ & 4 & 1.50 & 3.436 & $\begin{array}{l}\text { Non-clinical; adults, age=18- } \\
25\end{array}$ & 63 & 106 & $60 / 10$ \\
\hline $\begin{array}{l}\text { Kaiser et al. } \\
\text { (2019) }\end{array}$ & 10 & 2.00 & 6.204 & $\begin{array}{l}\text { Clinical depression; } \\
\text { adolescents, age=13-19 }\end{array}$ & 28 & $\begin{array}{l}\text { N.A., } \\
\text { referrals to local } \\
\text { psychological } \\
\text { services }\end{array}$ & $14 / 14$ \\
\hline
\end{tabular}




\begin{tabular}{|c|c|c|c|c|c|}
\hline $\begin{array}{l}\text { Moran et al. } \\
\text { (2019) }\end{array}$ & 4 & 6.50 & 6.673 & $\begin{array}{c}\text { Schizophrenia; adults, } \\
\text { age=mid-30s }\end{array}$ & 58 \\
\hline $\begin{array}{l}\text { Rattel et al. } \\
\text { (2019) }\end{array}$ & 8 & 4.00 & 6.204 & $\begin{array}{c}\text { Non-clinical; adults, } \\
\text { age }=22.9^{i}\end{array}$ & 53 \\
\hline $\begin{array}{l}\text { Scholz et al. } \\
\text { (2019) }\end{array}$ & 4 & 1.50 & 4.267 & $\begin{array}{c}\text { Non-clinical } \text {; adults, } \\
\text { age }=19-33\end{array}$ & 52 \\
\hline $\begin{array}{l}\text { Schwartz et al. } \\
\text { (2019) }\end{array}$ & 7 & 8.50 & 4.839 & $\begin{array}{c}\text { Clinical depression; adults, } \\
\text { age }=18-35\end{array}$ & 64 \\
\hline $\begin{array}{l}\text { Tost et al. } \\
\text { (2019) }\end{array}$ & 11 & 22.00 & 24.884 & $\begin{array}{l}\text { Non-clinical; adults, age }=18- \\
28\end{array}$ & 52 \\
\hline $\begin{array}{l}\text { Alarcon et al. } \\
\text { (2020) }\end{array}$ & 6 & 1.00 & 6.464 & $\begin{array}{l}\text { Non-clinical; adolescents, } \\
\text { age }=14-18\end{array}$ & 45 \\
\hline $\begin{array}{l}\text { Blaine et al. } \\
(2020)\end{array}$ & 7 & 5.00 & 18.112 & $\begin{array}{l}\text { Alcohol use disorder; adults, } \\
\text { age }=21-60\end{array}$ & 69 \\
\hline $\begin{array}{l}\text { Culbreth et al. } \\
(2020)\end{array}$ & 5 & 2.00 & 7.169 & $\begin{array}{c}\text { Schizophrenia; adults, } \\
\text { age }=37^{i}\end{array}$ & 28 \\
\hline $\begin{array}{l}\text { Heller et al. } \\
(2020)\end{array}$ & 7 & 15.00 & 24.884 & $\begin{array}{l}\text { Non-clinical; adults, age }=18- \\
31\end{array}$ & 58 \\
\hline $\begin{array}{l}\text { Hua et al. } \\
\text { (2020) }\end{array}$ & 6 & 5.00 & 2.376 & $\begin{array}{l}\text { Mood disorders; adults, } \\
\text { age }=25^{\mathrm{i}}\end{array}$ & 26 \\
\hline $\begin{array}{l}\text { Kronke et al. } \\
\text { (2020) }\end{array}$ & 7 & 4.00 & 3.139 & $\begin{array}{l}\text { Non-clinical; adults, age=19- } \\
27\end{array}$ & 294 \\
\hline $\begin{array}{l}\text { Martin-Soelch } \\
\text { et al. (2020) }\end{array}$ & 11 & 0.00 & 4.157 & $\begin{array}{l}\text { At-risk for depression; } \\
\text { adults, age=18-40 }\end{array}$ & 32 \\
\hline $\begin{array}{l}\text { Oppenheimer } \\
\text { et al. (2020) }\end{array}$ & 7 & 15.00 & 2.350 & $\begin{array}{c}\text { Clinical anxiety; adolescents, } \\
\text { age }=11-16\end{array}$ & 36 \\
\hline $\begin{array}{l}\text { Uy \& Galvan } \\
\text { (2020) }\end{array}$ & 2 & 1.00 & 6.464 & $\begin{array}{l}\text { Non-clinical; adolescents } \\
\text { and adults, age }=15-30\end{array}$ & 38 \\
\hline
\end{tabular}

\begin{tabular}{|c|c|c|c|c|}
\hline N.A. & $28 / 7$ & Affect, reward processing & Reward processing & EMA before MRI \\
\hline - & $\mathrm{NA} / 4^{\mathrm{m}}$ & $\begin{array}{l}\text { Affect, psychopathology } \\
\text { symptoms }\end{array}$ & Emotion processing & MRI before EMA \\
\hline 105 & $90 / 30$ & $\begin{array}{l}\text { Social interactions, affect, } \\
\text { substance use }\end{array}$ & Regulation/inhibition & MRI before EMA \\
\hline N.A. & $105 / 21$ & $\begin{array}{l}\text { Social interactions, affect, } \\
\text { psychopathology } \\
\text { symptoms }\end{array}$ & Resting state & MRI before EMA \\
\hline- & $87 / 7$ & Affect & Emotion processing & EMA before MRI \\
\hline- & $28 / 10$ & Social interactions, affect & Social reward & MRI before EMA \\
\hline- & $14 / 14$ & Substance use & Regulation/inhibition & MRI before EMA \\
\hline N.A. & $28 / 7$ & Reward processing & Reward processing & - \\
\hline N.A. & $22-78 / 3-4$ & Affect, sleep & Resting state & EMA before MRI \\
\hline 400 & $100 / 11-16$ & Affect & Emotion processing & MRI before EMA \\
\hline 47 & $56 / 7$ & Self-regulation & Resting state & - \\
\hline $\begin{array}{l}\text { N.A., } \\
\text { experimental } \\
\text { ours for study } \\
\text { plans }\end{array}$ & $28 / 7$ & Affect & $\begin{array}{l}\text { Reward processing, } \\
\text { emotion processing }\end{array}$ & MRI before EMA \\
\hline N.A. & $28 / 10$ & Affect & Social & EMA before MRI \\
\hline N.A. & $42 / 14$ & Affect & Social & $\begin{array}{l}\text { MRIs during EMA } \\
\text { period }\end{array}$ \\
\hline
\end{tabular}




\begin{tabular}{|c|c|c|c|c|c|c|c|c|c|c|}
\hline $\begin{array}{l}\text { Vekaria et al. } \\
\text { (2020) }\end{array}$ & 9 & 5.00 & 4.027 & $\begin{array}{l}\text { Non-clinical; adults, age }=21- \\
55\end{array}$ & 48 & N.A. & $14 / 14$ & Social interactions & Social & MRI before EMA \\
\hline $\begin{array}{l}\text { Woods et al. } \\
(2020)\end{array}$ & 7 & 0.00 & 2.083 & $\begin{array}{c}\text { Non-clinical; adolescents, } \\
\text { age }=14-18\end{array}$ & 48 & N.A. & $28 / 10$ & Affect & Social & EMA before MRI \\
\hline
\end{tabular}

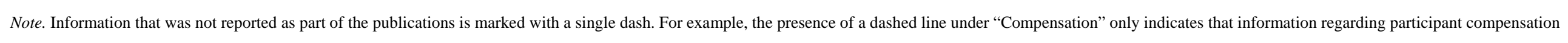
was not reported in the publication; it is not representative of authors explicitly stating that participants were not compensated.

${ }^{\mathrm{a}}$ Includes the first author and the year of publication

${ }^{b}$ The number of authors listed for the publication

${ }^{\mathrm{C}}$ The number of citations per year for each publication as of July 2021

d Includes the 2020 impact factor for the journal in which each study is published, extracted from Journal Citation Reports.

e Describes the population of interest and the age range of participants in years. For clinical populations, the diagnostic group of interest is listed.

f Size of the sample that completed both EMA and fMRI, and were included in analyses for each paper

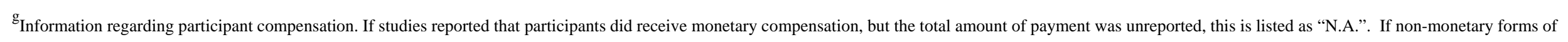
compensation were offered to participants, these are described. For studies that reported the maximum amount of payment participants could receive, all sums are listed in USD

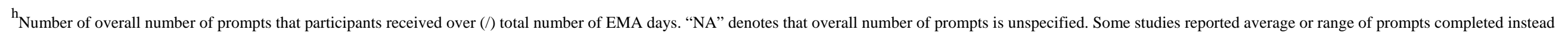
of overall number of prompts; in those cases the average or range are reported the right side of the dash (/).

${ }^{\mathrm{i}}$ Some papers reported the mean age of participants whose data was included in analyses (in years) rather than the age range of participants

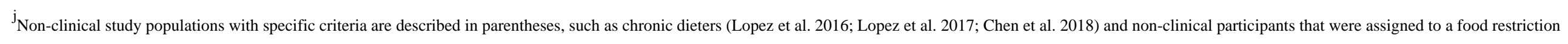
intervention as part of the study (Giuliani et al. 2015)

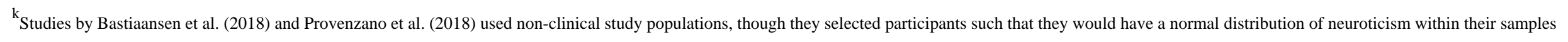

l Scholz et al. (2019) selected young adult participants who reported drinking a standard drink containing alcohol at least 2-3 times per month or more for the last 12 months 


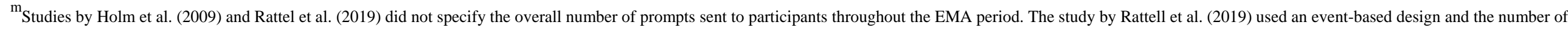
overall EMA prompts differed between participants

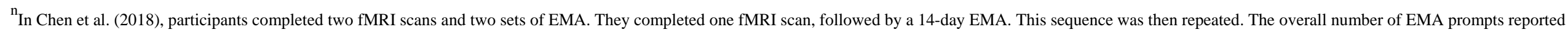
represents one 14-day EMA period 
Figure 1. PRISMA 2009 Flow Diagram
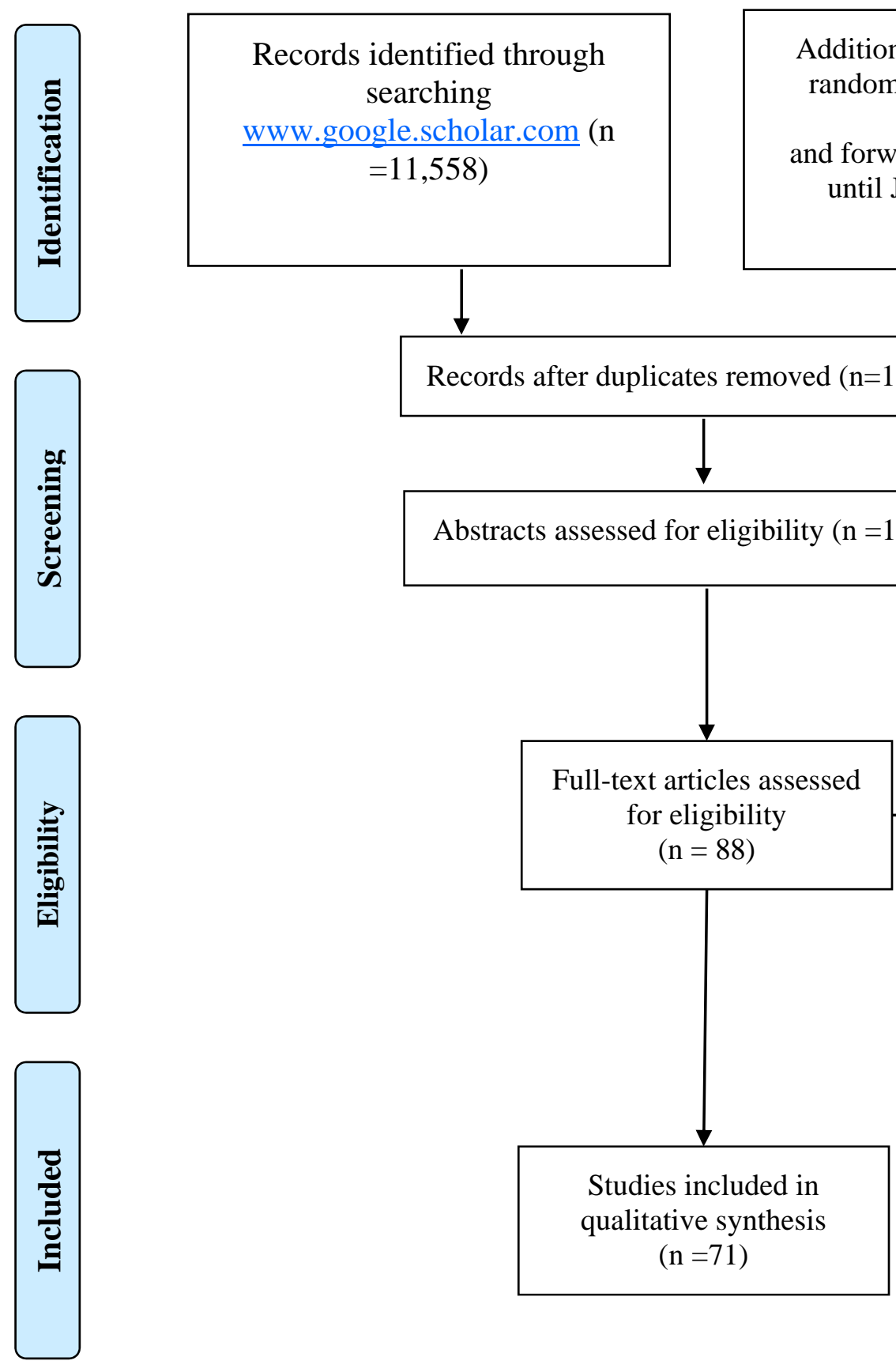
Figure 2. Number of Identified Papers Published Each Year, 2007-2020

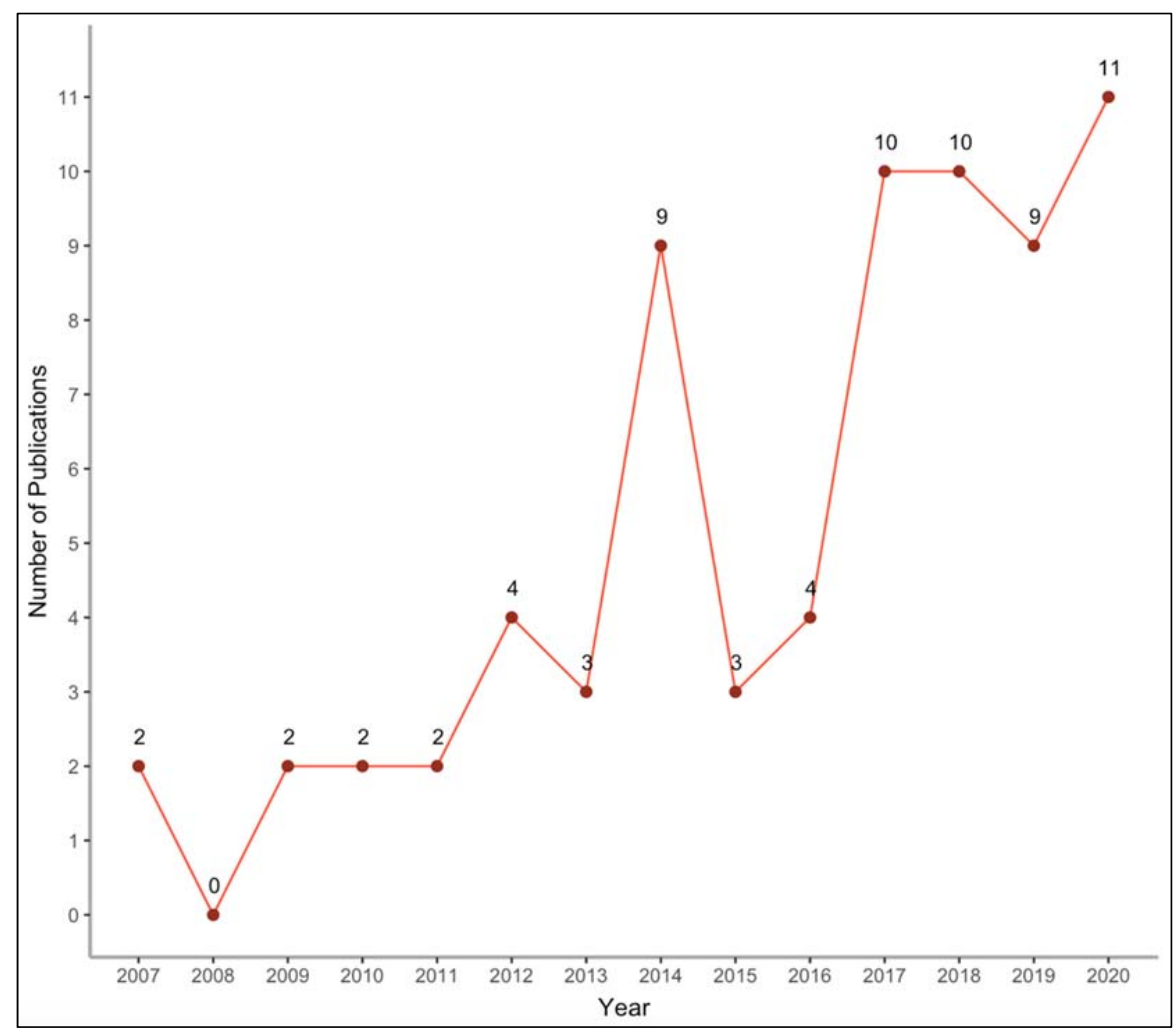


Figure 3. Place of Publication for Studies Combining EMA and MRI/fMRI, 2007-2020

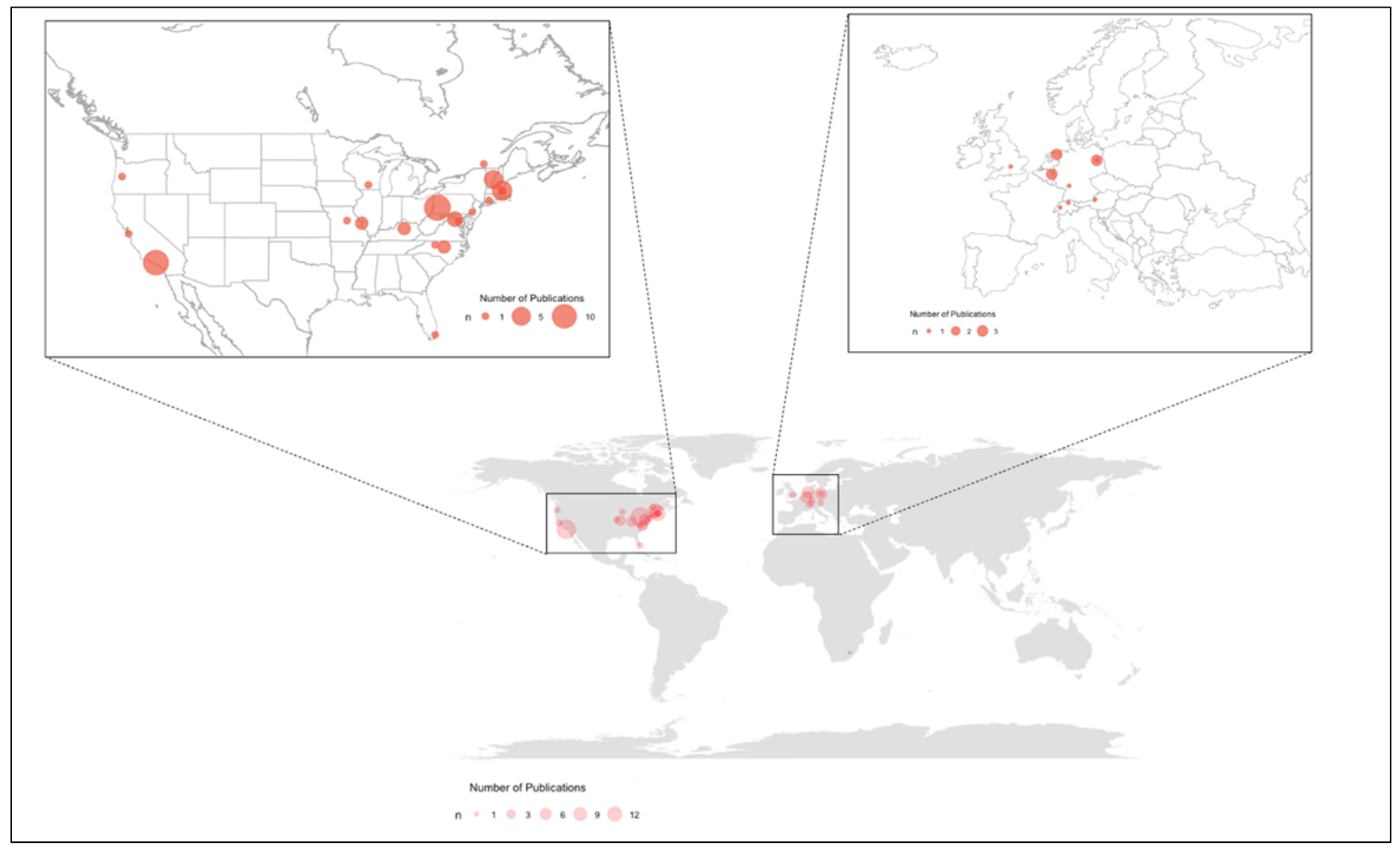


Figure 4. Four Study Designs Used to Combine EMA with MRI/fMRI.

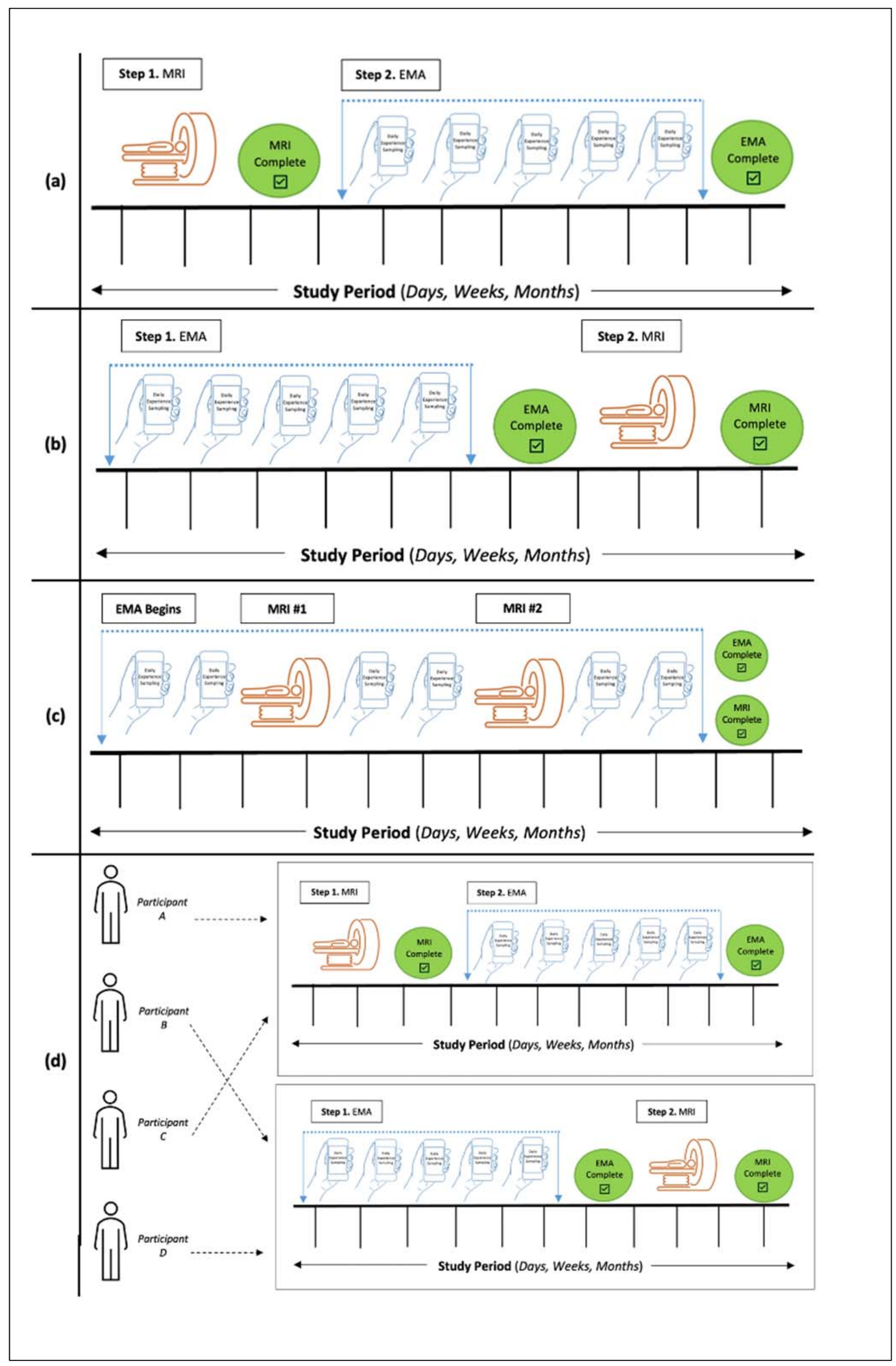

